Running head: Nature connectedness and emotion regulation

Psychopathy moderates the relationship between nature connectedness and cognitive reappraisal

Dean Fido ${ }^{1,2^{*}}$, Alice Rees ${ }^{2,3}$, Louise Wallace ${ }^{4}, \&$ Lamprini Mantzorou ${ }^{2}$

' Department of Criminology and Social Sciences, University of Derby (UK)

2 University of Derby Online Learning, University of Derby (UK)

${ }^{3}$ School of Philosophy, Psychology, and Language Sciences, University of Edinburgh (UK)

${ }^{4}$ Department of Psychology, Nottingham Trent University (UK)

Correspondence concerning this article should be addressed to Dr. Dean Fido, Department of Criminology and Social Sciences, University of Derby, One Friar Gate Square, Derby, DE1 1DZ, UK.

Tel.: +44 (1332) 597861. Email: deanfido.psych@gmail.com 


\begin{abstract}
The innate relationship that humans share with the natural world is becoming increasingly strained. Our connection to nature - reflected through the psychological construct of nature connectedness - has been shown to benefit areas of physical and mental wellbeing; of which, several relationships are thought to be mediated by ones' adaptive ability to regulate emotion. Emerging research has also indicated that nature connectedness and proficiency in emotion regulation share inverse relationships with deviant personality traits, such as psychopathy. However, it remains to be seen whether psychopathy, specifically, has a moderating role on the association between nature connectedness and emotion regulation. Three-hundred and nine participants completed an online survey whereby they were asked to self-report nature connectedness, emotion regulation strategy use, and psychopathy. Pearson correlations indicated a positive association between scores on nature connectedness and the use of cognitive reappraisal, but not expressive suppression strategies; a relationship found to be weaker in individuals scoring higher in psychopathy through moderation analysis. Evidence reported here support our hypotheses and indicate the necessity to acknowledge a more diverse array of personality constructs both when discussing the potential benefits of nature connectedness, and when testing the efficacy of nature-based interventions as a means of bringing about health- and wellbeing-related change.
\end{abstract}

Key words: nature connectedness; cognitive reappraisal; expression suppression; emotion regulation; psychopathy 


\section{Psychopathy moderates the relationship between nature connectedness and cognitive reappraisal}

\section{Introduction}

After having spent much of our evolutionary history within the natural environment, there now exists a great strain on the innate relationship that humans are thought to share with the natural world (Nisbet \& Zelenski, 2013a; Wilson, 1984). This perceived interconnection with nature can be captured through cognitive and affective dimensions; represented through the underlying psychological construct of nature connectedness (Capaldi, Dopko, \& Zelenski, 2014, Schultz, 2001). It has been well documented that exposure to nature leads to a wide range of health benefits (see Sandifer, Sutton-Grier, \& Ward, 2015, for a review). However, it is not only exposure to nature that is beneficial for an individual's health and wellbeing but also their perceived connection with nature. Indeed, those who report having a strong connection with nature and feel that they are a part of nature report a greater number of physical and mental wellbeing benefits such as increased happiness, positive affect, life satisfaction, and vitality (Capaldi et al., 2014; Cervinka, Röderer, \& Hefler, 2012; Martyn \& Brymer, 2016; Nisbet, Zelenski, \& Murphy 2011; Passmore \& Holder, 2017; Richardson et al., 2016; Ryan et al., 2010) than those who report lower levels of nature connection. The benefits of connecting with nature are beginning to influence governmental policies in order to increase people's connection (for example the United Kingdom's 25 Year Environment Plan, H.M. Government, 2018). Although there is an increasing consensus around the importance of nature connection and the benefits that arise from this connection, how the benefits arise is less clear (Cleary, Fielding, Bell, Murray, \& Roiko, 2017).

One potential explanation is through emotion regulation; the emotions an individual has, when and how emotion is experienced, and how emotion is expressed (Gross, 2002). 
Gross's (2002) process model is a dominant theory of emotion regulation which posits that emotion regulation can occur through a combination of cognitive reappraisal and expressive suppression strategies. Cognitive reappraisal strategies involve the reinterpretation of thoughts or stressors to improve mood via neutralising emotional situations. Expressive suppression, however, refers to controlling emotions by not suppressing them rather than expressing them. Of the two, cognitive reappraisal is considered a more adaptive and healthier approach to emotion regulation (Gross, 2002). Expressive suppression leads individuals to ruminate; contributing to lower self-esteem, poorer life satisfaction, and psychopathology (Aldao, Nolen-Hoeksema, \& Schweizer, 2010; Gross \& John, 2003). Poor emotion regulation is implicated in a larger number of mental health disorders such as anxiety and depression (Gross \& Muñoz, 1995; Jazaieri, Urry, \& Gross, 2012). Whereas, successful emotion regulation is linked to a range of positive health outcomes such as: improved immune responses, reduced illness frequency, and decreased risk of coronary heart disease (DeSteno, Gross, \& Kubzansky, 2013; Fredrickson et al., 2000; Gross et al., 2013).

One of the facets of nature connectedness pertains to emotions, specifically the affective relationship an individual has with nature. Nature connectedness has been positively associated with emotion regulation through its role in maintaining affective relationships with nature and the integration of such relationships in one's sense of self (Jordan, 2009; Lumber, Richardson, \& Sheffield, 2017). Where benefits can be seen, they are often greater in those who are more emotionally attuned with nature (Zhang, Piff, Iyer, Koleva, \& Keltner, 2014); reflecting an important link between the natural world and emotions.

Empirical research into the relationship between nature connectedness and emotion regulation is still in its infancy. Initial work by Johnsen \& Rydstedt (2013) found that exposure to nature imagery, and more specifically the active use of nature imagery during reflection or emotive situations, led to increases in positive mood (but not decreases in 
negative mood), which in turn was also predicted by intention to seek out nature when in a positive mood. More recently, exploratory work by Richardson and McEwan (2018) found that emotion regulation mediated the relationship between nature connectedness and subjective wellbeing (see also Richardson, McEwan, Maratos, \& Sheffield, 2016). Further, Richardson and Rees (2019) have suggested that one's level of nature connectedness may differentially predict a preference for emotion regulation strategy. Specifically, those reporting higher nature connectedness were more likely to use cognitive reappraisal strategies, whereby those reporting lower nature connectedness were more likely to use expressive suppression strategies. The link between nature connectedness and emotion regulation strategies is important and has opened up some interesting questions around the role and potential use of nature in a number of situations. One implication is how nature connection might be utilised to aid with emotion regulation. Of interest to the current paper is the potential link between nature connectedness and the dysfunction of emotion processing in psychopathology.

Adult psychopathology is thought to be underpinned by the presence of long-term and pervasive dysfunction in core processes involving emotion (Aldao et al., 2010) and is prevalent in those who report high levels of psychopathy (Hare \& Neumann, 2008; Patrick, Fowles, \& Krueger, 2009). Psychopathy is thought to manifest on a continuum within the general population, with those scoring highly characterised by [a] shallow emotion processing, $[\mathrm{b}]$ inappropriate affective responses to aversive stimuli, and [c] a limited capacity for sharing empathic experiences with others (Patrick, 2007; Viding \& McCory, 2019). Moreover, psychopathy is strongly associated with both reactive and proactive forms of aggression (Blais, Solodukhin, \& Forth, 2014), and so presents an important area of study in the investigation of emotion regulation. Of note, conceptualisations of psychopathy vary within the literature; ranging from super-ordinate constructs ('psychopathy'), to individual 
facets, including affective and interpersonal (primary) and lifestyle and antisocial (secondary) dimensions. Although literature discussed within this article varies across these conceptualisations, in line with Garofalo, Neumann, and Velotti (2020), this study uses the composite construct of psychopathy due to its greater relevance for tailoring discussions in public (as well as criminal justice) arenas (see Reidy et al., 2015).

In the general population, research into associations between psychopathy and emotion regulation is scarce. Burns, Roberts, Egan, \& Kane (2015) found that both primary and secondary dimensions of psychopathy were inversely related to cognitive reappraisal strategy use, and positively related to expressive suppression strategy use. Moreover, Garofalo et al. (2020) found that through mediation analysis, emotion dysregulation more generally accounted for some of the variation in the relationships between psychopathy and anger, hostility, and physical (but not verbal) aggression. Such findings reflect similar trends in forensic settings (Casey, Rogers, Burns, \& Yiend, 2013; Garofalo, Neumann, \& Velotti, 2018; Heinzen, Koehler, Smeets, Hoffer, \& Huchzermeier, 2011), where psychopathic traits are positively associated with the use of maladaptive emotion regulation strategies (including, but not specific to expressive suppression). Moving forward, and in line with Garofalo et al.'s (2020) urge to explore emotion regulation as a potential target for treatment intervention in reducing the adverse impact of psychopathy, work distinguishing between specific emotion regulation strategy use is timely and important.

A growing body of research has also begun to outline relationships between nature connectedness and psychopathy. While nature connectedness is positively associated with traits thought to be deficient in psychopathy such as agreeableness, perspective-taking, and empathic concern (Fido \& Richardson, 2019; Lynam \& Derefinko, 2006; Zhang et al., 2014), it is negatively associated with hallmarks of psychopathy, such as callous and uncaring traits (Fido \& Richardson, 2019). Moreover, across two independent samples, Fido et al. (2019) 
not only evidenced specific inverse relationships between nature connectedness and psychopathy (after controlling for social connectedness more generally), but also showed a preference for individuals scoring high on psychopathy to reside in inner-city, relative to suburban or rural areas whereby access to, and reliability on nature is less; similar to findings reported in Jonason (2018). Nevertheless, the precise mechanism by which nature connectedness and psychopathy are associated remains unknown. Based on the evidence reviewed, the link between nature connectedness and psychopathy is likely to lie in emotion.

The current study seeks to develop our understanding of the link between nature connectedness and psychopathy. It is expected that this link will lie in emotion regulation and will be examined by [1] delineating associations between nature connectedness and both cognitive reappraisal and expressive suppression strategy use and [2] exploring whether the relationships between each emotion regulation strategy and nature connectedness are moderated by variation in psychopathy. Nature connectedness was hypothesized to positively associate with cognitive reappraisal and negatively associate with both expressive suppression and psychopathy scores. Moreover, it was further hypothesized that any observed positive relationship between nature connectedness and cognitive reappraisal would be reduced in participants reporting greater levels of psychopathy.

\section{Methods}

\section{Participants}

An a priori power analysis, using the averaged effect sizes of previously-reported relationships between nature connectedness and psychopathy-related personality traits (Fido \& Richardson, 2019; Fido et al., 2019) suggested that around 296 participants were required to have $80 \%$ power in the planned analyses $\left(\mathrm{G}^{*}\right.$ Power, v3.1, $\left.\mathrm{f}^{2}=.037, \alpha=.05\right) .309 \mathrm{UK}$ based participants $\left(M_{a g e}=30.34\right.$ years, $S D=10.60$; age range $=18-66$ years; $49.2 \%$ female $)$, 
completed an online questionnaire advertised through the crowdsourcing website Prolific. Prolific-generated data is shown to be comparable in quality to [1] that obtained through laboratory settings and [2] alternative crowdsourcing websites such as Amazon's Mechanical Turk (Peer, Brandimarte, Samat, \& Acquisti, 2017). On average, the study took around 10 minutes to complete and participants were reimbursed with $£ 0.80$ for their participation. No participant reported any current diagnosis of psychiatric or neurological disorder likely to impact the nature of the study.

\section{Procedure and materials}

This research was approved by a central university research ethics committee. Participants reported demographic information (nationality, sex, and age) before completing an online battery of questionnaires comprising the Nature Relatedness Scale (NRS6; Nisbet \& Zelenski, 2013b), the Emotion Regulation Questionnaire (ERQ; Gross \& John, 2003), and the Short Dark Triad (SD3; Jones \& Paulhus, 2014).

The NRS6 comprises 6 items (e.g., "I always think about how my actions affect the environment'') that measure one's connectedness to nature using a 5-point scale $(1=$ Disagree Strongly, 5 = Agree Strongly). Scores range from 5 to 30 and higher scores indicate greater connectedness to nature. The ERQ is scored on a 7-point scale $(1=$ Strongly

Disagree, 7 = Strongly Agree $)$ and is formed of two dimensions that assess reappraisal (6 items; e.g., "I control my emotions by changing the way I think about the situation I'm in"; range 6 to 42) and suppression regulation strategies (4 items; e.g., "I control my emotions by not expressing them"; range 4 to 28). Higher scores indicate greater emotion regulation strategy use. The SD3 is a quick-to-administer ( 9 items), composite measure of psychopathy (e.g., "People who mess with me always regret it"), that is mean-scored using a 5-point scale $(1=$ Strongly Disagree, $5=$ Strongly Agree $)$. Higher scores are indicative of greater psychopathy. Although the SD3 also has the capacity to measure Machiavellianism (e.g., 
"Make sure your plans benefit you, not others") and narcissism (e.g., "I insist on getting the respect I deserve"), for this investigation, only psychopathy-relevant items were scored, analysed, and reported.

\section{Statistical analysis}

Pearson correlations were computed between the predictor variable (nature connectedness), the criterion variables (cognitive reappraisal and expressive suppression strategies), and the moderator variable (psychopathy). To determine whether psychopathy moderated the relationship between nature connectedness and emotion regulation strategies, we used Model 1 of the PROCESS plugin for SPSS (version 3.3; Hayes, 2018) to run two moderation models (one for each emotion regulation strategy). All regression coefficients for moderation models reported in this paper are unstandardized, as recommended in Hayes (2018), and were bootstrapped using 5000 samples. Confidence intervals were not bias corrected.

\section{Results}

\section{Correlation Analyses}

Nature connectedness was positively associated with the use of cognitive reappraisal strategies and negatively associated with psychopathy scores. However, nature connectedness was not associated with expressive suppression strategies; a finding also corroborated through post-hoc Bayesian testing with strong evidence in favour of the null hypothesis, $\mathrm{BF}_{10}$ $=0.225$. The use of expressive suppression, but not cognitive reappraisal strategies was positively associated with psychopathy scores. Means, standard deviations, alpha coefficients, and bivariate correlations for are displayed in Table 1. 
Table 1. Intercorrelations, means, standard deviations, and alpha coefficients for psychometric measures.

\begin{tabular}{|c|c|c|c|c|c|c|c|}
\hline & $\alpha$ & $\mathrm{M}$ & SD & 1 & 2 & 3 & 4 \\
\hline 1 Nature connectedness & .84 & 3.37 & .90 & - & & & \\
\hline 2 Cognitive reappraisal & .85 & 28.53 & 6.35 & $.29 * * *$ & - & & \\
\hline 3 Expressive suppression & .79 & 16.46 & 5.19 & -.06 & -.05 & - & \\
\hline 4 Psychopathy & .74 & 2.22 & .67 & $-.42 * * *$ & -.11 & $.20 * * *$ & - \\
\hline
\end{tabular}

\section{Moderation Analyses}

Model 1 accounted for $9.7 \%$ of the variance in the use of cognitive reappraisal strategies for emotion regulation, and was statistically significant, $F(3,305)=10.92, p<$ .001. As indicated in Table 2, nature connectedness positively predicted the use of cognitive reappraisal strategies. Further, although not a significant predictor itself, there was a significant interaction between nature connectedness and psychopathy scores such that associations between nature connectedness and use of cognitive reappraisal strategies were weaker in participants scoring 'high' on psychopathy; defined as being one SD above the sample mean (see Fig 1; Hayes, 2018).

Table 2. Moderation coefficients for cognitive reappraisal (Model 1).

\begin{tabular}{lcccc}
\hline & $B(\mathrm{SE})$ & $t$ & $p$ & $95 \% \mathrm{CI}(B)$ \\
\hline Nature connectedness & $2.23(.37)$ & 5.19 & $<.001$ & {$[1.39,3.08]$} \\
Psychopathy & $-.18(.43)$ & -.31 & .76 & {$[-1.34, .98]$} \\
Nature connectedness x Psychopathy & $-1.20(.52)$ & -2.31 & .02 & {$[-2.22,-.18]$} \\
\hline
\end{tabular}




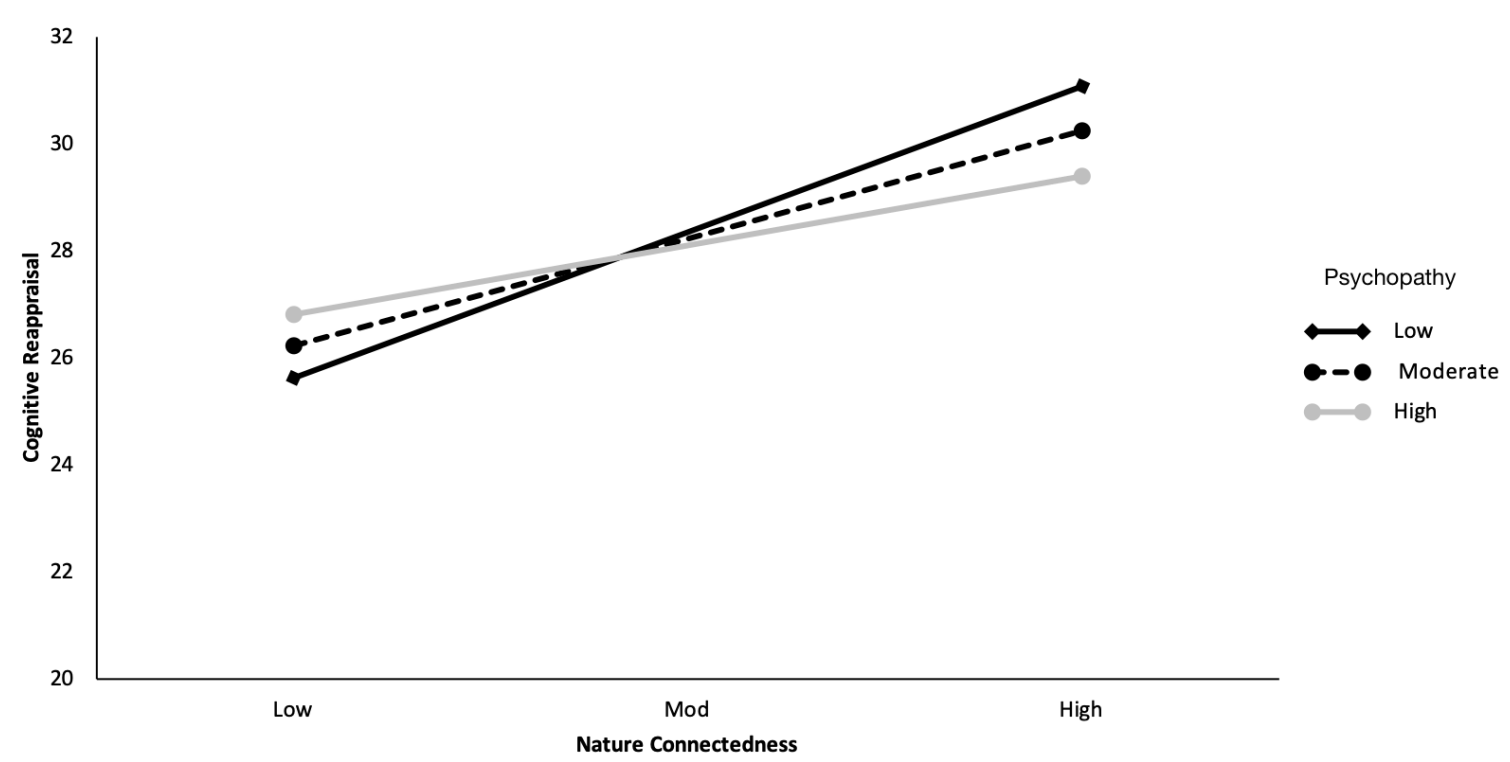

Fig 1. Effects of nature connectedness on cognitive reappraisal strategy use, by low (M1SD), medium (M), and high (M+1SD) psychopathy scores (Hayes, 2018).

Model 2 accounted for $4.8 \%$ of the variance in the use of expressive suppression strategies for emotion regulation, and was statistically significant, $F(3,305)=5.13, p=.002$. As indicated in Table 3, psychopathy, but neither nature connectedness nor their interaction, positively predicted the use of expressive suppression strategies. Post-hoc testing suggested that both models held after controlling for age and sex.

Table 3. Moderation coefficients for expressive suppression (Model 2).

\begin{tabular}{lcccc}
\hline & $B(\mathrm{SE})$ & $t$ & $p$ & $95 \%$ CI $(B)$ \\
\hline Nature connectedness & $.07(.36)$ & .19 & .85 & {$[-.64, .78]$} \\
Psychopathy & $1.84(.49)$ & 3.72 & $<.001$ & {$[.87,2.81]$} \\
Nature connectedness x Psychopathy & $-.61(.44)$ & 1.39 & .17 & {$[-.25,1.46]$} \\
\hline
\end{tabular}

\section{Discussion}

This investigation provides insight into the relationships between nature connectedness and distinct emotion regulation strategies as a function of psychopathy. In line 
with our hypotheses, nature connectedness was positively associated with the use of cognitive reappraisal strategies and negatively associated with psychopathy scores. However, there were no significant associations between nature connectedness and the use of expressive suppression strategies. Moreover, and as expected, associations between nature connectedness and cognitive reappraisal strategy use were weaker in individuals with high, relative to low, psychopathy scores.

The positive association between self-reported nature connectedness and the use of cognitive reappraisal strategies for emotion regulation closely replicates recent correlational data reported elsewhere (Richardson \& Rees, 2019) and adds to the limited research looking at how nature connection is involved in wellbeing (e.g. Cleary et al., 2017, Richardson et al., 2016). Emotion is one of the key pathways to nature connectedness, indeed nature connection can be increased through fostering an emotional relationship with nature. Given the potential benefits of adopting cognitive reappraisal strategies for the purpose of emotion regulation (Gross \& John, 2003), nature, or connection thereto, might represent an important conduit for emotion regulation interventions in the future. Such research is supported more broadly by literature noting the beneficial roles of exposure to nature (Johnsen \& Rydstedt, 2013) and feeling connected with nature (Richardson \& McEwan, 2018) in increasing positive mood and facilitating wellbeing. What was unexpected, however, was the absence of an inverse association between nature connectedness and the use of emotion suppression strategies as seen in Richardson and Rees (2019). With scarce research in this area, it is unclear why this finding was not replicated; however, it is important to note that post-hoc Bayesian analysis suggested that this finding should be attributed to a null effect rather than a lack of power. Further, although restricted in terms of the spread of scores (see Table 1.), psychopathy was found to be negatively associated with nature connectedness and moderated the relationship between nature connectedness and cognitive reappraisal strategy use, with 
this relationship was weaker in individuals reporting higher psychopathy. Previously, nature connectedness has not only been associated with traits thought to be deficient in psychopathy such as agreeableness, perspective-taking, and empathic concern (Fido \& Richardson, 2019; Zhang et al., 2014), but has also been negatively associated with self-reported callous and uncaring traits, as well as psychopathy specifically (Fido et al., 2019; Fido \& Richardson, 2019); mirroring results obtained here. As such, the moderation effects reported here likely indicate a psychopathy-driven dampening effect on one's ability to form and maintain authentic affective relationships with nature (Jordan, 2009; Viding \& McCory, 2019); reflected elsewhere through inverse associations between psychopathy and both empathy and compassion (Jonason \& Krause, 2013; Jonason \& Kroll, 2015).

To a small, but significant magnitude, psychopathy was positively associated with the use of expressive suppression emotion regulation strategies. Such findings mirror positive relationships observed between psychopathy scores and the use of maladaptive emotion regulation strategies in the general population (Burns et al., 2015) as well as juvenile forensic samples (Heinzen et al., 2011). Given that expressive suppression strategies are widely considered to be maladaptive and associated with poorer life outcomes, the development of psychopathology, and aggressive behaviour (Aldao, Nolen-Hoeksema, \& Schweizer, 2010; Garofalo et al., 2020; Gross, 2002; Gross \& John, 2003; Gross \& Muñoz, 1995; Jazaieri et al., 2012), accurately delineating contributors to this association is an important next step. Combined with the lack of any association between psychopathy and cognitive reappraisal use (an association which was present, negatively, in Burns et al., 2015), it might be that individuals with higher psychopathy scores are processing stressors and potential situational outcomes qualitatively differently from their low psychopathy-scoring counterparts (e.g., Dalkner et al., 2018) and so have little use for cognitive reappraisal strategies. Of interest, although this data suggests a greater use of expressive suppression in individuals with higher 
psychopathy scores, it does not inform on whether such individuals are subject to the same negative outcomes (Gross \& John, 2003).

\section{Limitations and Future Research}

Limitations of this research and associated future avenues of investigation are discussed below. First, unlike in study one of Fido et al. (2019), this investigation did not control for variation in social connectedness when delineating correlates of nature connectedness. Although the relationship between nature connectedness and psychopathy outlined in Fido et al. (2019) held after controlling for social connectedness, suggesting a unique role of nature, it remains to be seen whether social connectedness might play a role in the relationship between nature connectedness and use of emotion regulation strategies. Second, given items of the NRS6 rely strongly on self-reported affective reactions to nature, it would have been desirable to also consider the measurement of more general affective tendencies; allowing us to better contextualise and understand the nature of the observed results. Third, measurement of emotion regulation varied in comparison to recent literature (Garofalo et al., 2018; 2020), which used the Difficulties in Emotion Regulation Scale (DERS; Gratz \& Roemer, 2004); a measure of broader emotion regulation strategy use that does not allowed for the distinct assessment of reappraisal and suppression strategy use, specifically. Finally, all data were self-reported and cross-sectional in nature; a particular problem for the measurement of psychopathy due to its strong relationship with deception and poor emotional self-insight (Sellbom, Lilienfeld, Fowler, \& McCrary, 2018). As such, future replication should both consider the use of combining self- with other-reported measures to increase response validity, as well as implementing experimental manipulations of emotion regulation (e.g., Casey et al., 2013; Yiend et al., 2008) as a means of allowing for a better understanding of dynamic proficiency in emotion regulation strategy use. That being 
said, it is worth noting that self-reported emotion regulation is considered by some to be a representative method of accessing emotion regulation strategy due to laboratory settings often providing on a single, unnatural situation (Garnefski, Koopman, Kraaij, \& ten Cate, 2009; Garnefski \& Kraaij, 2007).

\section{Conclusion}

This study is the first to investigate the moderating role of psychopathic personality on the relationship between nature connectedness and emotion regulation. Indeed, individuals with higher levels of self-reported psychopathy evidenced weaker relationships between nature connectedness and the use of cognitive reappraisal strategies; an adaptive form of emotion regulation. Moreover, psychopathy was positively associated with the use of expressive suppression strategies; a maladaptive form of emotion regulation. Given the role of emotion dysregulation in violent behaviour (see Miles et al., 2017 for a review), results reported here provide further rationale and practical implications for research into naturebased interventions for reducing violence. Such interventions may include the cost- and resource-efficient 'Three Good Things Nature Intervention' (Richardson \& Sheffield, 2017), which to date, has not been used in the context of antisocial or violent behaviour. However, considering current results, there is a clear need to acknowledge the moderating role of personality when predicting and evaluating the benefit of nature. 


\section{Funding}

This work received internal financial support from the University of Derby Undergraduate Research Scholarship Scheme awarded to the corresponding author.

\section{Attribution}

This work should be attributed to the University of Derby, Department of Criminology and Social Sciences, One Friar Gate Square, Derby, DE1 1DZ, UK.

\section{Author Disclosure Statement}

The authors declared no potential competing interests with respect to the research, authorship, and/or publication of this article. 


\section{References}

Aldao, A., Nolen-Hoeksema, S., \& Schweizer, S. (2010). Emotion-regulation strategies across psychopathology: A meta-analytic review. Clinical Psychology Review, 30, 217-237. https://doi.org/10.1016/j.cpr.2009.11.004.

Blais, J., Solodukhin, E., Forth, A. E. (2014). A meta-analysis exploring the relationship between psychopathy and instrumental versus reactive violence. Criminal Justice and Behavior, 41(7), 797-821. https://doi.org/10.1177/0093854813519629.

Burns, S., Roberts, L. D., Egan, S., \& Kane, R. (2015). Evaluating emotion processing and trait anxiety as predictors of non-criminal psychopathy. Personality and Individual Differences, 81, 148-154. https://doi.org/10.1016/j.paid.2014.08.044.

Capaldi, C. A., Dopko, R. L., \& Zelenski, J. M. (2014). The relationship between nature connectedness and happiness: A meta-analysis. Frontiers in Psychology, 5. https://doi.org/10.1007/s10902-019-00118-6.

Casey, H., Rogers, R. D., Burns, T., \& Yiend, J. (2013). Emotion regulation in psychopathy. Biological Psychology, 92, 541-548.

https://doi.org/10.1016/j.biopsycho.2012.06.011.

Cervinka, R., Röderer, K., \& Hefler, E. (2012). Are nature lovers happy? On various indicators of well-being and connectedness with nature. Journal of Health Psychology, 17(3), 379-388. https://doi.org/10.1177/1359105311416873.

Cleary, A., Fielding, K. S., Bell, S. L., Murray, Z., \& Roiko, A. (2017). Exploring potential mechanisms involved in the relationship between eudaimonic wellbeing and nature 
connection. Landscape and Urban Planning, 158, 119-128.

https://doi.org/10.1016/j.landurbplan.2016.10.003

Dalkner, N., Reininghaus, E. Z., Riedrich, K., Rieger, A., Birner, A., Fellendorf, F. T., ... Reininghaus, B. (2018). Psychopathic personality factor "Fearless dominance" is related to low self-reported stress-levels, fewer psychiatric symptoms, and more adaptive stress coping in psychiatric disorders. Psychiatry Research, 270, 68-77. https://doi.org/10.1016/j.psychres.2018.09.018.

DeSteno, D, Gross, J. J., \& Kubzansky, L. (2013). Affective science and health: The importance of emotion and emotion regulation. Health Psychology, 32(5), 474-86. https://doi.org/10.1037/a0030259.

Fido, D., Rees, A., Clarke, P., Petronzi, D., \& Richardson, M. (2019, August 6). Examining the connection between nature connectedness and dark personality. https://doi.org/10.31234/osf.io/shd7v.

Fido, D., \& Richardson, M. (2019). Empathy mediates the relationship between nature connectedness and both callous and uncaring traits. Ecopsychology, 11(2). https://doi.org/10.1089/eco.2018.0071.

Fredrickson, B. L., Mancuso, R. A., Branigan, C., \& Tugade, M. M. (2000). The undoing effect of positive emotions. Motivation and Emotion, 24(4), 237-258. https://doi.org/10.1023/a:1010796329158.

Garnefski, N., Koopman, H., Kraaij, V., \& ten Cate, R. (2009). Brief report: Cognitive emotion regulation strategies and psychological adjustment in adolescents with a chronic disease. Journal of Adolescence, 32, 449-454. https://doi.org/10.1016/j.adolescence.2008.01.003. 
Garnefski, N. \& Kraaij, V. (2007). The cognitive emotion regulation questionnaire. Psychological Assessment, 23, 141-149. https://doi.org/10.1027/1015-5759.23.3.141.

Garofalo, C., Neumann, C. S., \& Velotti, P. (2018). Difficulties in emotion regulation and psychopathic traits in violent offenders. Journal of Criminal Justice, 57, 116-125. https://doi.org/10.1016/j.jcrimjus.2018.05.013.

Garofalo, C., Neumann, C. S., \& Velotti, P. (2020). Psychopathy and aggression: The role of emotion dysregulation. Journal of Interpersonal Violence. https://doi.org/10.1177/0886260519900946.

Gratz, K. L. \& Roemer, L. (2004). Multidimensional assessment of emotion regulation and dysregulation: Development, factor structure, and initial validation of the Difficulties in Emotion Regulation Scale. Journal of Psychopathology and Behavioral Assessment, 36, 41-54. https://doi.org/10.1023/B:JOBA.0000007455.08539.94.

Gross, J. J. (2002). Emotion regulation: Affective, cognitive, and social consequences. Psychophysiology, 39, 281-291. https://doi.org/10.1017/s0048577201393198.

Gross, J. J. (2013). Emotion regulation: Taking stock and moving forward. Emotion, 13, 359365. https://doi.org/10.1037/a0032135.

Gross, J. J. \& John, O. P. (2003). Individual differences in two emotion regulation processes: Implications for affect, relationships, and well-being. Journal of Personality and Social Psychology, 85, 348-362. https://doi.org/10.1037/0022-3514.85.2.348.

Gross, J. J. \& Munoz, R. F. (1995). Emotion regulation and mental health. Clinical Psychology Science and Practice, 2, 151-164. https://doi.org/10.1111/j.14682850.1995.tb00036.x. 
Hare, R. D. \& Neumann, C. S. (2008). Psychopathy as a clinical and empirical construct. Annual Review of Clinical Psychology, 4, 217-246.

https://doi.org/10.1146/annurev.clinpsy.3.022806.091452.

Hayes, A. F. (2018). Introduction to mediation, moderation, and conditional process analysis. (2nd Ed.). New York: The Guilford Press.

Heinzen, H., Koehler, D., Smeets, T., Hoffer, T., \& Huchzermeier. C. (2011). Emotion regulation in incarcerated young offenders with psychopathic traits. The Journal of Forensic Psychiatry \& Psychology, 22(6), 809-833.

https://doi.org/10.1080/14789949.2011.623171.

H.M. Government. (2018). A Green Future: Our 25 Year Plan to Improve the Environment, available at: http://www.gov.uk/government/publications/25-year-environment-plan (accessed 1 December 2019).

Jazaieri, H., Goldin, P. R., Werner, K., Ziv, M., \& Gross, J. J. (2012). A randomized trial of MBSR versus aerobic exercise for social anxiety disorder. Journal of Clinical Psychology, 68, 715-731. https://doi.org/10.1002/jclp.21863.

Johnsen, S. Å. K. \& Rydstedt, L. W. (2013). Active use of the natural environment for emotion regulation. Europe's Journal of Psychology, 9, 798-819. https://doi.org/10.5964/ejop.v9i4.633.

Jonason, P. K. (2018). Bright lights, big city: The Dark Triad traits and geographical preference. Personality and Individual Differences, 132, 66-73. https://doi.org/10.1016/j.paid.2018.05.024. 
Jonason, P. K. \& Krause, L. (2013). The emotional deficits associated with the Dark Triad traits: Cognitive empathy, affective empathy, and alexithymia. Personality and Individual Differences, 55, 532-537. https://doi.org/10.1016/j.paid.2013.04.027.

Jonason, P. K. \& Kroll, C. H. (2015). A multidimensional view of the relationship between empathy and the Dark Triad. Journal of Individual Differences, 36, 150-156. https://doi.org/10.1027/1614-0001/a000166.

Jones, D. N. \& Paulhus, D. L. (2014). Introducing the Short Dark Triad (SD3): A brief measure of dark personality traits. Assessment, 21(1), 28-41. https://doi.org/10.1177/1073191113514105.

Jordan, M. (2009). Nature and self-An ambivalent attachment? Ecopsychology, 1, 26-31. https://doi.org/10.1089/eco.2008.0003.

Lumber, R., Richardson, M., \& Sheffield, D. (2017). Beyond knowing nature: contact, emotion, compassion, meaning, and beauty are pathways to nature connection. PLoS One: 12, e0177186. https://doi.org/10.1371/journal.pone.0177186.

Lynam, D. R. \& Derefinko, K. J. (2006). Psychopathy and personality. In C.J. Patrick (Ed), Handbook of Psychopathy (pp. 133-155). New York Guilford Press.

Martyn, P. \& Brymer, E. (2016). The relationship between nature relatedness and anxiety. Journal of Health Psychology, 21(7), 1436-1445. https://doi.org/10.1177/1359105314555169.

Miles, S. R., Sharp, C., Tharp, A. T., Stanford, M. S., Stanley, M., Thompson, K. E., \& Kent, T. A. (2017). Emotion dysregulation as an underlying mechanism of impulsive aggression: Reviewing empirical data to inform treatments for veterans who 
perpetrate violence. Aggression and Violent Behavior, 34, 147-153.

https://doi.org/10.1016/j.avb.2017.01.017.

Nisbet, E. K. \& Zelenski, J. M. (2013a). Underestimating nearby nature: Affective forecasting errors obscure the happy path to sustainability. Psychological Science, 22, 1101-1106. https://doi.org/10.1177/0956797611418527.

Nisbet, E. K. \& Zelenski, J. M. (2013b). The NRS6: A new brief measure of nature relatedness. Frontiers in Psychology, 4. https://doi.org/10.3389/fpsyg.2013.00813.

Nisbet, E. K., Zelenski, J. M., \& Murphy, S. A. (2011). Happiness is in our nature: Exploring nature relatedness as a contributor to subjective well-being. Journal of Happiness Studies, 12, 303-322. https://doi.org/10.1007/s10902-010-9197-7.

Passmore, H. \& Holder, M. D. (2017). Noticing nature: Individual and social benefits of a two-week intervention. Journal of Positive Psychology, 12, 537-546. https://doi.org/10.1080/17439760.2016.1221126.

Patrick, C. J. (2007). Getting to the heart of psychopathy. In H. Herve and J. C. Yuile (Eds), The Psychopath: Theory, Research, and Social Implications (pp 207-252). Erlbaum, Hillsade, NJ.

Patrick, C. J., Fowles, D. C., \& Krueger, R. F. (2009). Triarchic conceptualization of psychopathy: Developmental origins of disinhibition, boldness, and meanness. Development and Psychopathology, 21(3), 913-938. https://doi.org/10.1017/S0954579409000492.

Paulhus, D. L., Neumann, C. S., \& Hare, R. D. (2016). Manual for the Self-Report Psychopathy Scale (4th ed.). Toronto: Multi-Health Systems. 
Peer, E., Brandimarte, L., Samat, S., Acquisti, A. (2017). Beyond the Turk: Alternative platforms for crowdsourcing behavioral research. Journal of Experimental Social Psychology, 70, 153-163. https://doi.org/10.1016/j.jesp.2017.01.006.

Reidy, D. E., Kearns, M. C., DeGue, S., Lilienfeld, S. O., Massetti, G., Kiehl, K. A. (2015). Why psychopathy matters: Implications for public health and violence prevention. Aggression and Violent Behavior, 24, 214-225. https://doi.org/10.1016/j.avb.2015.05.018.

Richardson, M., Cormack, A., McRobert, L., \& Underhill, R. (2016). 30 days wild: Development and evaluation of a large-scale nature engagement campaign to improve well-being. PLoS One, 11(2), e0149777. https://doi.org/10.1371/journal.pone.014977.

Richardson, M. \& McEwan, K. (2018). 30 Days Wild and the relationships between engagement with nature's beauty, nature connectedness and well-being. Frontiers in Psychology, 9. https://doi.org/10.3389/fpsyg.2018.01500.

Richardson, M., McEwan, K., Maratos, F., \& Sheffield, D. (2016). Joy and calm: How an evolutionary functional model of affect regulation informs positive emotions in nature. Evolutionary Psychological Science, 2(4), 308-320. https://doi.org/10.1007/s40806-016-0065-5

Richardson, M. \& Rees, A. (2019). Nature connectedness, emotional regulation, and ecological concern in mental well-being. (submitted, Journal of Happiness Studies).

Richardson, M. \& Sheffield, D. (2017). Three good things in nature: Noticing nearby nature brings sustained increases in connection with nature. PsyEcology, 8, 1-32. https://doi.org/10.1080/21711976.2016.1267136. 
Ryan, R. M., Weinstein, N., Bernstein, J., Brown, K. W., Mistretta, L., \& Gagne, M. (2010). Vitalizing effects of being outdoors and in nature. Journal of Environmental Psychology, 30, 159-168. https://doi.org/10.1016/j.jenvp.2009.10.009.

Sandifer, P. A., Sutton-Grier, A. E., \& Ward, B. P. (2015). Exploring connections among nature, biodiversity, ecosystem services, and human health and well-being: Opportunities to enhance health and biodiversity conservation. Ecosystem Services, 12, 1-15. https://doi.org/10.1016/j.ecoser.2014.12.007.

Schultz, P. W. (2001). Assessing the structure of environmental concern: Concern for the self, other people, and the biosphere. Journal of Environmental Psychology, 21, 327339. https://doi.org/10.1006/jevp.2001.0227.

Sellbom, M., Lilienfeld, S. O., Fowler, K. A., \& McCrary, K. L. (2018). The self-report assessment of psychopathy: Challenges, pitfalls, and promises. In C. J. Patrick (Ed.), Handbook of psychopathy (pp. 211-258). The Guilford Press.

Viding, E. \& McCrory, E. (2019). Towards understanding atypical social affiliation in psychopathy. The Lancet. Psychiatry, 6, 437-444. https://doi.org/10.1016/S22150366(19)30049-5.

Wilson, E. O. (1984). Biophilia. Cambridge, MA: Harvard University Press.

Yiend, J., Mathews, A., Weston, B., Dunn, B. D., Cusack, R., \& Mackintosh, B. (2008). An investigation of the implicit control of the processing of negative pictures. Emotion, 8(6), 828-837. https://doi.org/10.1037/a0014146. 
Zhang, J. W., Piff, P. K., Iyer, R., Koleva, S., \& Keltner, D. (2014). An occasion for unselfing: Beautiful nature leads to prosociality. Journal of Environmental Psychology, 37, 61-72. https://doi.org/10.1016/j.jenvp.2013.11.008. 